\title{
Dimensão PSICOSSOCIAL DA ATIVIDADE FÍSICA NA VELHICE
}

Maria da Silva Santana ${ }^{\star}$

\section{ReSUMO}

Objetivou-se identificar as representações sociais da atividade fisica no contexto dos programas para a terceira idade no municipio de Natal (RN), Brasil. Foi feito um estudo transversal de abordagem quanti-qualitativa.Por conveniência, a amostra não probabilística foi constituida de 70 individuos. Na coleta dos dados, utilizou-se um questionário com dados sociodemográficos, associação livre de palavras e questão aberta. O núcleo central da representação foi composto por felicidade/saúde/dança e ginástica, revelando diferentes entendimentos e mostrando também que o conhecimento construído da atividade física assume um papel preponderante na vida de idosos, adquirindo, gradativamente, a representação de "vida com mais saúde e qualidade na velhice". A composição do núcleo central ao considerar elaborações mentais, emoções, práticas e explicações oriundas do cotidiano que se introduzem na constituição da representação social em foco, poderá influenciar as escolhas e estratégias de se desenvolver melhora nos padrões de saúde e na qualidade de vida dos idosos.

Palavras-chave: envelhecimento; saúde do idoso; Psicologia Social.

\section{Psychosocial Dimension OF PHYSICAL ACTIVITY IN THE OLDNESS}

\begin{abstract}
Aim to identify the social representations of physical activity in the context of programs for the elderly in Natal (RN), Brazil. A study Cross-sectional quantitative and qualitative. A non-probability sample and for convenience was formed by seventy individuals. In data collection we used a questionnaire with demographic data, free association of words and open question. The core of the representation was composed of happiness / health / dance and gymnastics, revealing different understandings and also showing that accumulated knowledge of physical activity plays a central role in the lives of older people, gradually acquiring the representation of "life with better health and quality in old age". The composition of the core when considering mental elaborations, emotions, practices and explanations arising from daily life that are introduced into the constitution of social representation in focus, can influence the choices and strategies to promote improvement in health standards and quality of life of elderly.
\end{abstract}

Keywords: aging; health of the elderly; Social Psychology.

\footnotetext{
^Educadora Física. Mestre em Ciências da Saúde/PPGCSa - Universidade Federal do Rio Grande do Norte. Docente da Secretaria Estadual de Educação Cultura e Desporto/SECD/RN e Universidade Estadual Vale do Acaraú/RN. Endereço: Conjunto Ponta Negra, Rua Baia das Canárias, 2234, Bairro Ponta Negra. Natal/RN, Brazil. CEP: 59092-295.

E-mail: mariasilvasantana@gmail.com.
} 


\section{INTRODUÇão}

Sabe-se que as questões do envelhecimento apresentam, atualmente, um fenômeno social de grande significado no contexto das sociedades em todo o mundo. Segundo o Instituto Brasileiro de Geografia e Estatística - IBGE (SANTANA, POUCHAIN, BISSI, 2000), no Brasil, para a segunda década deste século, projeta-se uma população de 32 milhões de idosos. Por outro lado, percebe-se importante relação entre sedentarismo com o aumento progressivo da idade, levando ao decréscimo da capacidade física (MATSUDO, 2001).

Nesse sentido, a promoção do estilo de vida mais ativo na terceira idade tem sido utilizada como estratégia para desenvolver melhora nos padrões de saúde e na qualidade de vida (FERREIRA et al, 2005), em que a prática de atividade física tem sido amplamente incentivada tendo em vista seus benefícios físicos e psicossociais (TEIXEIRA; OKUMA, 2004). No caso da terceira idade, há fortes evidências de que o idoso que se exercita obtém uma variedade de benefícios, inclusive menos enfermidades e aumento na capacidade de enfrentar o estresse diário (PEREIRA et al, 2006).

Sobre a importância social e científica de investigações a respeito das condições que favoreçam uma boa qualidade de vida na velhice, estudos ressaltam investigações entre velhice e bem-estar e entre velhice e doença. Para alguns autores, pesquisas desse tipo contribuem para a compreensão do envelhecimento e para a criação de novas intervenções que objetivem a promoção de bem-estar nessa fase da vida (MACIEL; GUERRA, 2006; BARBOSA et al, 2005).

Em pesquisas que investigam crenças, atitudes, percepções e representações sociais do velho, da velhice e do envelhecimento ainda se encontra a predominância de representações negativas acerca da velhice como também associação entre velhice e doença (VELOZ; NASCIMENTO-SCHULZE; CAMARGO, 1999; ARAÚJO; CARVALHO, 2004).

Na concepção de Freitas et al (2002), resultados semelhantes podem, inclusive, estar ligados ao contexto social, cuja representação do envelhecimento também pode ser cultural. Para esses autores, cada sociedade, de acordo com o tempo, num ciclo de valorização e desvalorização, atribui valores, interesses diferentes à pessoa idosa, à temática velhice e, consequentemente, ao envelhecer.

Sob essa perspectiva, a aparente desconsideração, no cotidiano das sociedades, das significações atribuídas ao bem-envelhecer a partir de um estilo de vida ativo, parece confirmar essas tendências. Entretanto, não leva em conta a relação da saúde com o fenômeno de representação social da atividade física a quem se destina: o idoso. Esse fenômeno, identificado no âmbito psicossocial por Moscovici (1978), é capaz de esclarecer aspectos discursivos das necessidades da atividade física para as práticas de saúde em geral (SHEPHARD, 2003; CARNEIRO et al, 2007; RIGO; TEIXEIRA, 2005), auxiliando a pesquisa sobre a Representação Social (RS) da Atividade Física (AF) na terceira idade. 


\section{As REPRESENTAÇÕES SOCIAIS (RS) E A TEORIA DO NÚCLEO CENTRAL}

Esta pesquisa indica que os benefícios da Atividade Física (AF) podem ser considerados como parte integrante da promoção de saúde na terceira idade. O estudo realizado, no entanto, limita-se à identificação de elementos imagéticos que evidenciam essa relação, sem deixar de tentar ampliar os seus possíveis significados.

A Teoria das Representações Sociais, introduzida por Serge Moscovici na França, em 1961, considera a representação social como, ao mesmo tempo, um processo psicossocial e o produto dele resultante, relacionando-a às comunicações e condutas sociais (MOSCOVICI, 1978). Assim sendo, se a AF representa e comunica a "ideia" de saúde, felicidade e bem-estar que alguns grupos concebem, ela pode ser considerada como produto da RS da atividade física desses grupos.

Para Moscovici (1978), a RS é uma modalidade de conhecimento particular que tem por função, entre outras, a elaboração de comportamentos e a comunicação entre indivíduos. E, se são uma "preparação para a ação", elas o são principalmente porque reconstituem os elementos do ambiente no qual o comportamento terá lugar, integrando-o a uma rede de relações às quais está vinculado seu objeto para estabilizá-las e torná-las mais eficazes. Daí a importância da prática da atividade física na terceira idade, em que os elementos subjetivamente percebidos pelos idosos possibilitam identificar os benefícios concretos dessa prática, facilitando a comunicação.

Segundo Jodelet (2002), as pesquisas sobre RS devem procurar compreender como o social interfere na elaboração psicológica da representação e viceversa. Moscovici (1981) responde a essa questão indicando os dois processos básicos que evidenciam a interdependência entre a atividade psicológica e suas condições sociais de exercício: a "ancoragem", responsável pela constituição de uma rede de significações em torno do objeto social; e a "objetivação", que corresponde à passagem de conceitos/ideias para esquemas/imagens concretas. $\mathrm{O}$ processo de ancoragem, dialeticamente relacionado à objetivação, articula três funções básicas da representação: a função cognitiva de integração da novidade, a função de interpretação da realidade e a função de orientação das condutas e das relações sociais (MOSCOVICI, 1981).

Assim, de acordo com a Teoria das RS, pode-se afirmar que um programa sistemático de AF para idosos - com resultados práticos quantificáveis para a saúde global - apresentados à sociedade constitui uma objetivação (concreta) de instituições (no caso deste estudo - CEFET/RN), a uma idealização (abstrata) dos benefícios da AF, construída no âmbito psicossocial dos grupos que a conceberam. Mesmo que o provável praticante da AF seja levado em consideração, o programa será projetado para atender a um usuário também representado, já que este não participa ativamente do processo decisório. Sabe-se, no entanto, que o elo de adesão ou não adesão do idoso às práticas do programa alimenta e é alimentado pelas imagens dos resultados dessas práticas. Logo, a cada "nova" formalização de projetos para a terceira idade, devem ser assimilados concretamente pelos idosos elementos imagéticos relacionados às Representações Sociais da Atividade Física. 
A Teoria do Núcleo Central, proposta em 1976 por Abric (1994), sustenta que toda representação está estruturada em torno de um núcleo que determina sua significação e sua organização interna. Em torno do núcleo central se organizam elementos periféricos cuja presença, ponderação, valor e função são determinados por ele (ABRIC, 1994). Entretanto, a posição nuclear ou periférica dos elementos não é fixa, podendo alterar-se ao longo do tempo segundo a valorização a eles atribuída em um determinado momento (SÁ, 1996). Essa valorização cognitivamente carregada vai contribuir mais ou menos para a mudança das relações sociocomportamentais estabelecidas pelos grupos para com os objetos de RS.

A questão que se apresenta, portanto, é até que ponto as necessidades e valor social das atividades físicas na percepção do idoso se colocam para as práticas de saúde global em benefício próprio a partir da RS da atividade física?

O conceito de representação permite explicar o lugar que ocupa a representação nas sociedades pensantes, a partir da distinção entre universos de conhecimentos consensuais e conhecimentos reificados: assim, o primeiro universo é constituído a partir de nossas experiências e de informações que recebemos e transmitimos através das tradições, da educação e da comunicação social entre os grupos. No universo reificado, a sociedade é vista como um sistema de diferentes papéis e classes (MOSCOVICI, 1981).

As pesquisas a respeito dos aspectos psicossociais da atividade física requerem, além da investigação puramente biológica, um melhor entendimento desses aspectos. Nessa perspectiva, este estudo teve por objetivo identificar as representações sociais da atividade física no contexto dos programas para a terceira idade na cidade de Natal (RN). Com isso, será possível apreender os diversos produtos mentais e culturais estruturados, com componentes cognitivo, afetivo, avaliativo e simbólico (entre outros), construídos no cotidiano das relações pessoais, que norteiam o comportamento e as atitudes dos sujeitos e dos grupos sociais em que se inscrevem de forma compartilhada (MOSCOVICI, 1978; JODELET, 2002).

A pesquisa foi desenvolvida de acordo com as Normas de Realização de Pesquisa em Seres Humanos, Resolução 196/96, do Conselho Nacional de Saúde(BRASIL, 1996), e avaliado pelo Comitê de Ética em Pesquisa da Universidade Federal do Rio Grande do Norte.

\section{Perspectiva metodológica}

O objeto da Representação Social está incluído num contexto ativo e dinâmico, sendo concebido pelo sujeito ou pela coletividade como prolongamento do seu comportamento. Dessa maneira, a representação social é uma "preparação para a ação", que remodela e recompõe os elementos do meio ambiente, estabelecendo um sentido para a ação (MOSCOVICI, 1978).

Visando complementar a teoria das Representações Sociais, a teoria do Núcleo Central, desenvolvida por Abric estabelece que as representações sociais se organizam em torno de um núcleo estruturante composto por um ou mais elementos, que dão significado à representação (ABRIC, 1994). Assim, o núcleo 
central também é denominado núcleo estruturante, possuindo duas funções basilares: a "geradora", necessária para que os elementos adquiram um sentido na representação e a "unificadora", que integra e estabiliza a representação.

O sistema central, ligado às condições históricas, sociológicas e ideológicas, desempenharia um papel mais estável e duradouro nas representações sociais e o sistema periférico, cujos elementos são responsáveis pela interface entre a realidade e o sistema central, posto que atualizam e contextualizam as determinações normativas e outras formas consensuais do núcleo central (ABRIC, 1994).

É essa interface que permite a mobilidade, a flexibilidade e a expressão individualizada que, igualmente, como afirma Sá, caracterizam as representações sociais (SÁ, 1996). Desse modo, sua determinação está mais ligada ao contexto imediato e às características individuais. Ou seja, o núcleo central é utilizado pelos indivíduos como referência para orientar suas apreensões e percepções sobre a vida social (ABRIC, 1994).

Foi realizado um estudo transversal, de abordagem quanti-qualitativa, para identificar as diferentes representações sociais dos sujeitos implicados com a experiência da atividade física, pondo em evidência os elementos representacionais centrais e periféricos das representações sociais em questão.

O campo de investigação foi o Programa "Saúde e Cidadania na terceira idade" (PSCTI), em funcionamento desde 2000, com sede no Centro de Educação Federal e Tecnológica do Rio Grande do Norte (CEFET), no município de Natal, (RN), Brasil, que ensina as pessoas com idade acima de 50 anos a prática da atividade física.

A amostra não probabilística e por conveniência foi constituída por 70 indivíduos, do sexo masculino e feminino, com idade acima de 50 anos, residentes na zona urbana do município de Natal (RN). Os critérios de inclusão dos sujeitos na pesquisa foram: assinatura do Termo de Consentimento Livre e Esclarecido e ser aluno regular do projeto por mais de um mês (JODELET, 2002).

Para a coleta do material, utilizou-se um questionário composto de três instrumentos: a primeira parte constou de dados sociodemográficos, tais como: idade, sexo, estado civil e escolaridade; a segunda, com a associação livre de palavras, para captar os elementos representacionais centrais e periféricos sobre o sentido da atividade física, a partir da frase indutora: "Escreva rapidamente cinco palavras que, em sua opinião, associam-se à atividade física". Essas palavras foram anotadas e em seguida numeradas por ordem de importância, na concepção dos sujeitos da pesquisa.

A técnica de associação livre de palavras é o mais antigo dos testes projetivos utilizados em psicologia clínica. Ajuda a localizar zonas de bloqueamento e de recalcamento de um indivíduo, permitindo que apareçam espontaneamente associações relativas às palavras exploradas (BARDIN, 2008). 
Segundo Abric (1994), é uma técnica importante para coletar elementos constitutivos do conteúdo de uma representação. A partir das evocações obtidas, foi possível seguir a análise sugerida pelo autor, ou seja, a investigação do conteúdo representacional, a estrutura e a organização desse conteúdo e a determinação e controle do núcleo central (ABRIC, 1994).

A terceira parte constituiu-se de uma questão aberta para a obtenção do material discursivo. Essa técnica favorece a compreensão das relações estabelecidas entre os atores sociais e a situação vivenciada. Para a questão, utilizamos a seguinte pergunta: "Por que você resolveu fazer parte de um projeto de atividade física?".

Para o tratamento dos dados, o conteúdo do questionário social foi analisado pelo software SPSS (IBM, 1999). As palavras coletadas no Teste de Associação Livre de Palavras, inicialmente, conforme preconiza Bardin (2008), foram organizadas através de um processo de agrupamento por classificação, reunindo as palavras próximas a nível semântico (palavras idênticas ou sinônimas) e em seguida foram submetidas a uma classificação por aproximação de sentido com o objetivo de estabelecer categorias de análise. O processo de estabelecimento dessas categorias foi realizado concomitantemente por três juízes externos, operando independentemente. Após esse processo, o material foi analisado pelo software Evoc 2000 para a obtenção dos núcleos central e periférico, que levaria à identificação da estrutura da representação, a partir da utilização da técnica do quadro de quatro quadrantes (VERGĖS, 1998).

Esse procedimento estabelece um esquema figurativo que possibilita a distribuição dos termos evocados em função de dois critérios : a frequência e a ordem média das evocações das palavras. Assim, obtém-se a Ordem Média de Evocação (OME) e a Frequência Intermediária (Fi) das palavras, que na seqüência são agrupadas em categorias através dos caracteres comuns desses elementos (SÁ, 1996).

A análise do material da questão aberta foi processada pelo software ALCESTE 4.5 - Analyse Lexicale par Contexte d'un Esemble de Segments de Texte (REINERT, 1990). Esse software agrupa raízes semânticas definindo-as por classes, levando em consideração a função da palavra dentro de um dado texto. Assim, tanto é possível quantificar, como inferir sobre a delimitação das classes, que são definidas em função da ocorrência e da coocorrência das palavras e da sua função textual.

Após a formatação do texto (corpus), segue a análise, que envolve, basicamente, quatro etapas operacionais: Etapa A: Leitura do Texto e Cálculo dos Dicionários; Etapa B: Cálculo das Matrizes de Dados e Classificação das Unidades de Contexto Elementar (UCE); Etapa C: Descrição das Classes de UCE; Etapa D: Cálculos Complementares (CAMARGO, 2005).

A contribuição do método de análise textual ALCESTE é significativa para o estudo das representações sociais, por possibilitar a interpretação de um volume considerável de dados textuais, bem como a possibilidade da triangulação de dados qualitativos e quantitativos. Partindo do pressuposto de que as representações sociais são entendidas como teorias compartilhadas pelo grupo 
que serve de referência - nesse caso, os alunos do programa "Saúde e Cidadania na Terceira Idade", buscou-se compreender a construção compartilhada que forma o senso comum desse grupo.

\section{Resultados}

Nesta pesquisa, observaram-se vários aspectos da vida e do comportamento dos sujeitos, descritos através da frequência (em percentagem) de respostas e em forma textual.

A amostra foi composta por 70 entrevistados, sendo 65 do sexo feminino e cinco do masculino. Essa predominância do sexo feminino é representativa nos grupos de convivência, conforme aponta também estudo de Areosa, Bevilacqua e Werner (2003). Quanto à idade, 55,7\% tinham entre 50 a 60 anos e 44,3\% entre 61 a 78 anos. O critério cronológico adotado para ingressar no programa pesquisado é a partir de 50 anos, o que justifica o número significativo de entrevistados com idade até 60 anos. Nesse estudo, incluímos todos os sujeitos da pesquisa na categoria de idoso para padronizar a linguagem. Quanto ao estado civil, encontrou-se que $31,4 \%$ eram viúvos, $45,7 \%$ eram casados e $22,9 \%$ estavam na condição de solteiro. Quanto à escolaridade, $32,9 \%$ possuíam o ensino fundamental, $45,7 \%$ o ensino médio e $21,4 \%$ o ensino superior. Não se encontraram homens nem mulheres analfabetas nesse estudo.

$\mathrm{Na}$ identificação da atividade física (AF) como protetor contra doenças, acharam a prática da AF indispensável para a saúde geral (50\%); que a AF está diretamente vinculada à prevenção de certas doenças $(60 \%)$, como pressão alta, colesterol alto e osteoporose. Quanto à autopercepção do conhecimento sobre a AF, a grande maioria afirmou que gostariam de aprender mais sobre os seus benefícios (93\%).

Quanto à fonte de informação sobre a prática da atividade física: 62\% foram por recomendação médica; $23 \%$ pelos Meios de Comunicação tipo TV, rádio, revista, jornal etc; $10 \%$ por Parentes/Amigos; e $8 \%$ por Professor/Instrutor. As atividades preferidas foram: Hidroginástica (77\%), Dança (50\%), Ginástica (32\%) e Natação (31\%).

As associações que emergiram quando se utilizou a frase indutora "Escreva, rapidamente, as palavras que na sua opinião associam-se à atividade física", totalizaram 310 evocações. A análise dessas evocações, feita por meio da observação da frequência simples de cada uma delas, revelou 240 palavras diferentes, correspondendo a uma média de cinco evocações por sujeito. Observou-se uma variação significativa das palavras evocadas, colocando em evidência a polissemia em relação ao objeto, conforme observado na Tabela 1 .

Tabela 1 - Sumário dos resultados da associação livre de palavras obtidas a partir das evocações dos 
idosos do Programa "Saúde e Cidadania na Terceira Idade”. Natal (RN).

\begin{tabular}{|l|r|}
\hline Número de evocações & 310 \\
\hline Número de palavras diferentes evocadas & 240 \\
\hline Média de evocação por sujeito & 3 \\
\hline Sujeitos que indicaram a palavra mais importante & 62 \\
\hline Total de sujeitos & 62 \\
\hline
\end{tabular}

Em seguida, através de classificação baseada em sinônimos ou proximidade semântica das palavras, fez-se a primeira aproximação ao corpus, possibilitando a representação gráfica dos resultados por meio de tabelas de frequências. Seguiuse, então, a classificação em unidades de significação, e, por conseguinte, a categorização, dando visibilidade à estrutura interna existente no corpus em análise.

$\mathrm{Na}$ sequência, foram evidenciados os elementos organizadores da representação através dos seguintes indicadores: a frequência do item evocado, a média de frequência da evocação e a importância do item para o sujeito. Assim, as palavras evocadas mais frequentemente e mais prontamente pelos sujeitos, provavelmente, compõem os elementos centrais das representações desses sujeitos acerca do tema.

Assim, com as ordens de classificação obtidas a partir da significação das palavras evocadas pelos sujeitos, surgiram as seguintes categorias: alongamento; amizade; bem-estar; caminhada; conhecimento; dança; disposição; felicidade; ginástica; hidroginástica; natação; passear; prazer; saúde e socialização (Tabela 2).

Tabela 2 - Evocações segundo a ordem de classificação e ordem média de evocação.

\begin{tabular}{|l|c|c|c|c|c|c|c|}
\hline \multicolumn{1}{|c|}{ Categorias } & $1^{\text {a }}$ evoc. & $2^{\text {a }}$ evoc. & $3^{\text {a }}$ evoc. & $4^{\text {a }}$ evoc. & $5^{\text {a }}$ evoc. & $\mathrm{f}(\mathrm{n})$ & OME* $^{*}$ \\
\hline 1. Alongamento & 0 & 2 & 1 & 2 & 2 & 7 & 3,57 \\
\hline 2. Amizade & 1 & 2 & 0 & 5 & 6 & 14 & 3,93 \\
\hline 3. Bem-estar & 4 & 4 & 5 & 1 & 3 & 17 & 2,71 \\
\hline 4. Caminhada & 1 & 5 & 6 & 1 & 1 & 14 & 2,71 \\
\hline 5. Conhecimento & 0 & 0 & 1 & 3 & 6 & 10 & 4,50 \\
\hline 6. Dança & 15 & 3 & 3 & 2 & 2 & 25 & 1,92 \\
\hline 7. Disposição & 2 & 1 & 4 & 4 & 5 & 16 & 3,56 \\
\hline 8. Felicidade & 10 & 6 & 4 & 9 & 5 & 34 & 2,79 \\
\hline 9. Ginástica & 4 & 6 & 6 & 3 & 1 & 20 & 2,55 \\
\hline 10. Hidroginástica & 6 & 3 & 6 & 4 & 3 & 22 & 2,77 \\
\hline 11. Natação & 0 & 5 & 2 & 1 & 1 & 9 & 2,78 \\
\hline 12. Passear & 0 & 4 & 2 & 0 & 2 & 8 & 3,00 \\
\hline 13. Prazer & 0 & 5 & 1 & 0 & 1 & 7 & 2,57 \\
\hline 14. Saúde & 15 & 5 & 5 & 2 & 0 & 27 & 1,78 \\
\hline 15. Socialização & 1 & 1 & 0 & 3 & 5 & 10 & 4,00 \\
\hline Totais & 53 & 55 & 49 & 40 & 43 & 240 & 38,00 \\
\hline Médias & 3,53 & 3,66 & 3,26 & 2,66 & 2,86 & 16,00 & 3,00 \\
\hline
\end{tabular}

*OME = Ordem Média de Evocação $\mathrm{f}=$ freqüência evoc. = evocação

Nesta perspectiva, a frequência de evocação foi calculada a partir do somatório das frequências com que a palavra foi evocada em cada posição, enquanto a ordem média de evocação foi obtida ponderando-se com o peso 1 a evocação feita em primeiro lugar, com peso 2 a segunda evocação e, assim, com tantas 
ponderações quantas foram associações solicitadas. O somatório desses produtos dividido pelo somatório das frequências da palavra citada nas diversas posições correspondeu à ordem de evocação da palavra. A média aritmética dos valores da ordem de evocação de cada palavra corresponde à ordem média de evocação. Procedendo à análise desses dois índices, de forma simultânea e combinada, foi possível revelar os elementos que provavelmente participam do núcleo central da representação devido à sua saliência (SÁ, 1996).

A partir desse procedimento, distribuíram-se os resultados obtidos em um diagrama de quatro quadrantes, de forma que o eixo horizontal se refere à ordem média de evocação (com os valores menores para o lado esquerdo do eixo) e o eixo vertical à freqüência de evocação (com os valores maiores dispostos na parte superior do eixo). Assim, o quadrante superior esquerdo foi composto pelas evocações de maior frequência e prontamente expressas; o inferior direito, pelas evocações de menor frequência e as mais tardiamente enunciadas. Os elementos que participam do núcleo central da representação situam-se no quadrante superior esquerdo (maior frequência e pronta evocação); já no quadrante inferior direito estão os de menor frequência, que são denominados de "elementos periféricos". Nos quadrantes superior direito e inferior esquerdo, situam-se os elementos que se relacionam menos diretamente com o núcleo central (VERGÈS, 1998).

De acordo com a análise combinada das indicações apontadas, em que a frequência média de evocação foi igual a 16 e a média aritmética das ordens médias de evocação foi igual a 3, delimitou-se a área de localização dos elementos que, provavelmente, participam do núcleo central e do sistema periférico da representação da atividade física, o que pode ser observado no Diagrama 1.

Diagrama 1 - Elementos constituintes do núcleo central e dos elementos periféricos da representação social da atividade física. Natal $(\mathrm{RN})$.

\begin{tabular}{|c|c|c|c|c|c|}
\hline \multicolumn{3}{|c|}{ Elementos do Núcleo Central } & \multirow{2}{*}{\multicolumn{3}{|c|}{ OME $>3 \quad F>16$}} \\
\hline \multirow{2}{*}{$\frac{\mathrm{OME}<3}{\text { Bem-estar }}$} & \multicolumn{2}{|c|}{$\mathrm{F}>16$} & & & \\
\hline & 7,06 & 17 & Disposição & 3,563 & 16 \\
\hline Dança & 1,920 & 25 & & & \\
\hline Felicidade & 2,794 & 34 & & & \\
\hline Ginástica & 2,550 & 20 & & & \\
\hline Hidroginástica & 2,773 & 22 & & & \\
\hline Saúde & 1,778 & 27 & & & \\
\hline $\mathrm{OME}<3$ & \multicolumn{2}{|c|}{$\mathrm{F}<16$} & \multicolumn{3}{|c|}{$\begin{array}{l}\text { Elementos Periféricos } \\
\text { OME }>3 \quad \mathrm{~F}<16\end{array}$} \\
\hline Caminhada & 2,714 & 14 & Alongamento & 3,571 & 7 \\
\hline Natação & 2,778 & 9 & Amizade & 3,929 & 14 \\
\hline \multirow[t]{3}{*}{ Prazer } & 2,571 & 7 & Conhecimento & 4,500 & 10 \\
\hline & & & Passear & 3,000 & 8 \\
\hline & & & Socialização & 4,000 & 10 \\
\hline
\end{tabular}

OME- Ordem Média de Evocação F: Frequência

Assim, os elementos "bem-estar; dança; felicidade; ginástica, hidroginástica e saúde" situam-se no quadrante superior esquerdo, por apresentarem uma maior saliência (maior Qui²) e, dessa forma, compõem o núcleo central da repre- 
sentação social da atividade física na terceira idade. Os elementos dos demais quadrantes tendem, por conseguinte, a representar os elementos periféricos da representação, que se relacionam menos diretamente com o núcleo central.

O material discursivo resultante da questão aberta foi submetido ao software ALCESTE 4.5 (CAMARGO, 2005). O processamento do corpus teve aproveitamento de 71,43\% do total das UCE (Quadro 1).

Quadro 1 - Relatório descritivo resumido produzido pela análise do corpus referente às Representações Sociais da atividade física por idosos do Grupo Saúde e Cidadania na Terceira Idade da cidade de Natal/RN. ( $\mathrm{n}=70)$.

\begin{tabular}{|l|c|}
\hline \multicolumn{1}{|c|}{ Nome do Corpus } & Atividade Física na Terceira Idade \\
\hline Número total de ocorrências & 2268 \\
\hline Formas distintas & 735 \\
\hline Formas reduzidas das análises & 647 \\
\hline Formas complementares & 213 \\
\hline Palavras principais & 102 \\
\hline Frequência média de uma forma & 3 \\
\hline Frequência máxima de uma forma & 121 \\
\hline Qui-quadrado mínimo por palavra & 2,00 \\
\hline Número de UCI & 70 \\
\hline Número de UCE selecionadas & 96 \\
\hline Número de classes obtidas & 5 \\
\hline UCE por classe & 80 UCE $(71,43 \%)$ \\
\hline
\end{tabular}

Depois, a Classificação Descendente Hierárquica determinou cinco classes temáticas, que podem ser observadas no Dendrograma 1.

Dendrograma 1 - Distribuição das cinco classes temáticas obtidas através da análise do corpus referente às representações sociais da atividade física na terceira idade da cidade de Natal/RN.
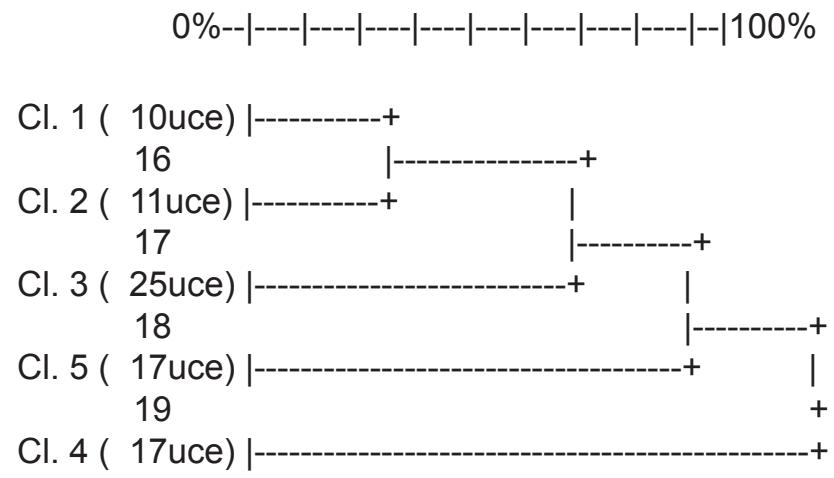

A finalidade dessa classificação é reunir as várias classes, de tal forma que exista homogeneidade dentro e heterogeneidade entre estas. O que se tem são as classes 1,2, 3 e 5 mantendo certo grau de associação, enquanto a classe 4 segue discriminada desde a primeira ramificação.

No Quadro 2, tem-se a descrição dessas classes através do conteúdo de cada uma. Para a interpretação do vocabulário específico das classes e suas respectivas temática, foram consideradas as palavras com frequência igual ou maior 
$(\geq)$ que 3 e Qui $^{2} \geq 3,84(\mathrm{gl}=1)$. Cada classe é descrita pelas palavras mais frequentes e pelas suas respectivas associações e porcentagens com a classe (Quiquadrado), cujos significados proporcionam o nível de interligação interclasses.

Quadro 2 - Perfil das Classes da Análise ALCESTE entre os idosos em relação ao tema "Atividades Físicas na Terceira Idade" com seu vocabulário específico. Natal/RN.

\begin{tabular}{|c|c|}
\hline $\begin{array}{l}\text { Classes, títulos e palavras de maior } \\
\left.\text { associação com a classe ( } \% \text { e } Q u i^{2}\right)\end{array}$ & $\begin{array}{l}\text { Exemplos de } \mathrm{UCE}^{*} \text { típicas da classe com as } \\
\text { palavras de maior associação em negrito }\end{array}$ \\
\hline $\begin{array}{l}\text { Classe } 1(10 \mathrm{UCE} / 12,50 \%) \text { - Mudança de } \\
\text { atitude } \\
\text { Problema }(66,67 \% \text { e } 8,36) \text {; Porque }(53,85 \% \\
\text { e } 24,26)\end{array}$ & $\begin{array}{l}\text { "porque me encontrava cheia de problemas e } \\
\text { muito ociosa me sentindo muito doente, hoje } \\
\text { estou livre da maioria dos pensamentos que } \\
\text { me atormentavam" (UCE 45)". }\end{array}$ \\
\hline $\begin{array}{l}\text { Classe } 2 \text { (10 UCE/13,75\%) - Autonomia } \\
\text { Conhecimento }(100 \% \text { e } 19,55)\end{array}$ & $\begin{array}{l}\text { "por isso que digo que a atividade fisica faz } \\
\text { bem, faz a gente ser independente (...), afinal } \\
\text { não somos inúteis" (UCE 104). }\end{array}$ \\
\hline $\begin{array}{l}\text { Classe } 3(25 \text { UCE/ } 12,50 \%) \text { - Felicidade } \\
\text { Aqui }(100 \% \text { e } 31,06) ; \text { Feliz }(100 \% \text { e } 11,73) \text {; } \\
\text { Feliz }(100 \% \text { e } 11,73) \text {. }\end{array}$ & $\begin{array}{l}\text { "agora, que os filhos estão crescidos, resolvi } \\
\text { cuidar de mim (...). Aqui sou muito, demais } \\
\text { feliz..." (UCE 84). }\end{array}$ \\
\hline $\begin{array}{l}\text { Classe } 4 \text { (17 UCE/21,25\%) - Qualidade de } \\
\text { vida } \\
\text { Vida }(55,56 \% \text { e } 28,66) ; \text { melhorar }(100 \% \text { e } \\
42,35) ; \text { qualidade }(73,33 \% \text { e } 29,93) .\end{array}$ & $\begin{array}{l}\text { "para ter uma qualidade de vida melhor" } \\
\text { (UCE 56). }\end{array}$ \\
\hline $\begin{array}{l}\text { Classe } 5(17 \text { UCE } / 21,25 \%) \text { - Estilo de vida } \\
\text { Tempo }(100 \% \text { e } 15,60) ; \text { sentir }(80 \% \text { e } 11,00) \text {; } \\
\text { importante }(100 \% \text { e } 11,55)\end{array}$ & $\begin{array}{l}\text { "(...) foi uma escolha, uma mudança na forma } \\
\text { de vida, existe (...) é como um resgate da } \\
\text { identidade, da saúde, do tempo, do social e da } \\
\text { qualidade de vida" (UCE 76). }\end{array}$ \\
\hline
\end{tabular}

${ }^{*}$ UCE - Unidades de Contexto Elementar

\section{DiscuSsão}

A estratégia metodológica utilizada ajuda a perceber além da natureza essencialmente coletiva na variação de sentido que cada sujeito atribui ao objeto representado (VERGÈS, 1998), no caso, a atividade física. Os elementos do sistema periférico (no quadrante inferior direito - Diagrama 1) fazem a interface entre a realidade e o núcleo central (no quadrante superior esquerdo - Diagrama 1) garantindo a ancoragem das representações sociais na realidade do momento. Desse modo, os elementos do núcleo central da atividade física representados por "Dança, felicidade e saúde" (Diagrama 1) revelam informações de um contexto imediato com características individuais (SÁ, 1996), normalmente, utilizados pelos indivíduos para referendar suas apreensões e percepções da vida social (ABRIC, 1994).

Os elementos periféricos, por sua vez, representaram certa aproximação do sentido atribuído à atividade física, ao incorporarem elementos como "amizade e conhecimento" ,o que pode indicar certa mudança ou ampliação de significados 
nos elementos do núcleo central. Como se vê nos seguintes depoimentos: "UCE 1036 sempre tive muito medo, inclusive de sair sozinha, pânico mesmo [...] pois dependia de outras pessoas para me trazer [...]e hoje estou aqui e me sinto tão bem" (Classe 3).Ou, "UCE 7812 porque aumenta a minha auto estima, me dá saúde, aumenta os meus conhecimentos"(Classe 2).

Diante do argumento relacionado ao termo "felicidade" (Quadro 2), percebe-se que já começa a haver uma ressignificação dos demais benefícios proporcionados pela atividade física na terceira idade. Pressupõe-se que, apesar das progressivas limitações que possam ocorrer nessa fase do desenvolvimento, as pessoas vislumbram redescobrir possibilidades de viver a própria vida com a máxima qualidade possível na medida em que não se restrinjam às suas vivências pessoais, fugindo do estereótipo da terceira idade ser considerada doentia, isolada e infeliz.

Okuma (1998) retrata bem essa realidade quando buscou compreender o significado da atividade física para o idoso a partir do enfoque fenomenológico. As descrições das experiências vividas confirmam a importância da atividade física, como: recurso para lidarem com eventos de vida, meio de autovalorização e atualização, recurso para melhorarem a saúde e a capacidade funcional, favorecendo a interação idoso-ambiente.

Conforme essa autora, isso significou mudanças essenciais no modo de ser dos idosos, em suas relações com o outro e com o mundo e na compreensão do próprio processo de envelhecimento como um momento de vida a ser vivido intensa e prazerosamente, modificando conceitos estereotipados internalizados sobre o que é ser velho e envelhecer.

Essa pode ser uma tendência importante no que concerne a essa fase da vida, em que, geralmente, as mudanças estruturais do corpo determinadas pelo envelhecimento têm implicações psicossociais que acarretam e geram manifestações de diferentes comportamentos, como inatividade, solidão, isolamento e preconceito. Realidade essa constatada no cenário brasileiro, onde ainda há a predominância de representações negativas acerca do envelhecimento e entre envelhecimento e doença (VELOZ; NASCIMENTO-SCHULZE; CAMARGO, 1999; ARAÚJO; CARVALHO, 2005).

Algumas categorias ou classes (UCE) que emergiram de maneira mais enfática, a partir da análise léxica (ALCESTE), reforçam as evocações que constituíram o núcleo central: para a categoria (evocação) "saúde", o sentido atribuído pelos sujeitos foi generalizado, algo repetido pelo senso comum no intuito de sintetizar em uma só expressão a dimensão biopsicossocial da atividade física: "UCE 4542 porque me encontrava cheia de problemas e muito ociosa me sentindo muito doente, hoje, estou livre da maioria dos pensamentos que me atormentavam, já tenho saúde" (Classe 1). "UCE 687 porque eu tinha medo de sair sozinha pensando que poderia morrer [...] e fiquei boa, livre de tal doença" (Classe 3). 
Há uma interface entre discursos e narrativas sobre a atividade física que circulam entre os idosos e que são constitutivas das teorias de senso comum, no afã de revelar estratégias para melhorar os padrões de saúde e a qualidade de vida (SHEPHARD, 2003; CARNEIRO et al., 2007). Como se vê no discurso para a categoria "bem-estar": "UCE 304 para ter relacionamento e crescimento no circulo de amizade e também para meu bem estar" (Classe 2).

Outro aspecto que mereceu destaque em nosso estudo foi sobre contatos sociais. Diz respeito à categoria "dança". Estudos atuais apontam que a capacidade de interagir socialmente é fundamental para o idoso, a fim de que este possa conquistar e manter apoio social e garantir melhor qualidade de vida (CARNEIRO et al., 2007), como se vê: "UCE 10115 eu gosto muito, mas muito mesmo é de dançar, e assim as coisas ruins vão todas embora" (Classe 3).

Estudos evidenciam que as relações sociais, em geral, o balanço das trocas e a integração social, em particular, têm implicações para a saúde mental na terceira idade. Que o bem estar não está simplesmente relacionado com o estado de saúde (RAMOS, 2007). Esse resultado é particularmente importante, já que os idosos no Brasil não tendem a participar de atividades sociais fora da esfera familiar, por causa das limitadas opções para atividades sociais na comunidade em geral.

\section{CONSIDERaÇões FINAIS}

Os resultados deste estudo foram positivos para a promoção da saúde, para a qualidade de vida e para um estilo de vida mais ativo de pessoas, a partir da Teoria das Representações Sociais e podem servir como estratégia de ação (MOSCOVICI, 1981).

Esta pesquisa constatou que os idosos do Projeto "Saúde e Cidadania na Terceira Idade, da cidade de Natal (RN), compartilham representações consensuais sobre a atividade física, cujo núcleo central foi composto pelos campos semânticos "felicidade, dança e saúde". Nesse processo, alguns idosos já começam a ressignificar outros elementos, incorporando significações novas ao objeto estudado (atividade física), como "bem-estar, disposição e amizade", provavelmente em função das experiências individuais, história de vida, inserção cultural e visão de mundo.

Essa nova forma de saber sugere que a atividade física, além de possibilitar às pessoas em processo de envelhecimento e aos já envelhecidos ultrapassarem os limites de saberes tradicionais e de conceitos estereotipados sobre a velhice, pode servir como elemento fundamental na estratégia de ganho de saúde e como balizador de metas em políticas públicas mais efetivas para a preservação da saúde e para a prevenção de doenças que acompanham o processo natural de envelhecimento. 


\section{REFERÊNCIAS}

ARAÚJO,L.F.; CARVALHO, V.A. M.L.Aspectos sócio-históricos epsicológicos da velhice. Mneme: Revista de Humanidades, Caicó, v.6, n.13, p. 228-236, jan. 2005 .

AREOSA, S. C.; BEVILACQUA, P.; WERNER, J. Representações sociais do idoso que participa de grupos para terceira idade no município de Santa Cruz do Sul. Estudos Interdisciplinares sobre o Envelhecimento, Porto Alegre, v. 5, p. 81-100, 2003.

ABRIC, J. C. L'organisation interne dês representations sociais: sistème central et système périfhérique. In: GUIMELLI G. (Org.). Structures et transformations des representações sociais. Neuchâtel: Delachaux et Niestlé, 1994. p. 73-84.

BARBOSA, A. R. et al. Functional limitations of Brazilian elderly by age and gender differences: data from SABE survey. Cadernos de Saúde Pública, Rio de Janeiro, v. 21, n. 4, p. 1177-1185, jul./ago. 2005.

BARDIN, L. Análise de Conteúdo. Tradução de Luiz Antero Reto e Augusto Pinheiro. São Paulo: Martins, 2008.

BRASIL. Resolução 196, de 10 de outubro de 1996. Aprova as diretrizes e normas regulamentadoras de pesquisas envolvendo seres humanos. Diário Oficial [da] República Federativa do Brasil, Brasília, DF, 16 out. 1996. Disponível em:< http:// conselho.saude.gov.br/resolucoes/reso_96.htm>. Acesso em: 29 dez. 2010.

CAMARGO, V. B. ALCESTE: um programa informático de análise quantitativa de dados textuais. Florianópolis: UFSC, 2005.

CARNEIRO, R. S. et al. Qualidade de Vida, Apoio Social e Depressão em Idosos: relação com habilidades sociais. Psicologia: Reflexão e Crítica, Porto Alegre, v. 20, n. 2, p. 229-237, maio/ago. 2007.

FERREIRA, M. et al. Efeitos de um programa de orientação de atividade física e nutricional sobre o nível de atividade física de Mulheres fisicamente ativas de 50 a 72 anos de idade. Revista Brasileira de Medicina do Esporte, Niterói, v. 11, n. 3, p. 172-176, maio/jun. 2005.

FREITAS, M. C. et al. Perspectivas das pesquisas em Gerontologia e Geriatria: revisão da literatura. Revista Latino-americana de Enfermagem, Ribeirão Preto, v. 10, n. 2, p. 214-220, mar./abr. 2002.

JODELET, D. As Representações Sociais: um domínio em expansão. In: (Org.). As Representações Sociais. 1. ed. Rio de Janeiro:EDUERJ, 2002. p. 17-44. 
MACIEL, A. C. C.; GUERRA, R. O. Prevalência e fatores associados à sintomatologia depressiva em idosos residentes no Nordeste Brasileiro. Jornal Brasileiro de Psiquiatria, Rio de Janeiro, v. 55, n. 1, p. 26-33, jan./mar. 2006.

MATSUDO, S. M. M. Atividade física e envelhecimento: aspectos epidemiológicos. In: Londrina: Midiograf; $\overline{2001 . p}$. 60-70.

MOSCOVICI, S. Representação Social da Psicanálise. Rio de Janeiro: Zahar, 1978.

MOSCOVICI, S. On social representation. In: FORGAS, J. P. (Org.). Social cognitions perspectivas na everyday understanting. New York: Academic, 1981. p. 181-209.

OKUMA, S. S. O idoso e a atividade física: fundamentos e pesquisa. Campinas: Papirus; 1998.

PEREIRA, R. J. et al. Contribuição dos domínios físico, social, psicológico e ambiental para a qualidade de vida global de idosos. Revista de Psiquiatria do Rio Grande do Sul, Porto Alegre, v. 28, n. 1, p. 27-38, jan./abr. 2006.

RAMOS, M. P. Os sintomas depressivos e as relações sociais na terceira idade. Revista do Departamento de Psicologia - UFF, v. 19, n. 2, p. 397-410, jul./dez. 2007.

REINERT, M. ALCESTE, une mèthologie d'analyse des données textuelles et une application: Aurélia de G. De Nerval. Bulletin de Méthodologie Sociologique, v. 26, p. 24-54, mar. 1990.

RIGO, M. L. N. R.; TEIXEIRA, D. C. Efeitos da atividade física na percepção de bem-estar de idosas que residem sozinhas e acompanhadas. UNOPAR Cient., Ciênc. Biol. Saúde, Londrina; v.7, n.1, p. 13-20, out. 2005.

SÁ, C. P. Núcleo Central das Representações Sociais. Petrópolis: Vozes; 1996.

SANTANA, R. L. F; POUCHAIN, G. C.; BISSI, L. F. A Previdência Social e o Censo 2000: Perfil dos idosos. Informe da Previdência Social-MS., Brasília-DF, vol. 14, n. 9, set. 2002. p. 01-20.

SHEPHARD, R. J. Envelhecimento, atividade física e saúde. Tradução Maria Aparecida da Silva Pereira Araújo. São Paulo: Phorte, 2003.

IBM. Statistical Packet for Social Science for Windows Release. Version 10.0.1. Standard Version. [S.1.]: Copyright. SPSS Inc. 1999. 
TEIXEIRA, D. C.; OKUMA, S. S. Efeitos de um programa de intervenção para idosos sobre a intenção de estudantes de educação física de trabalhar com este grupo etário. Revista Brasileira de Educação Física e Esporte, São Paulo, v. 18, n. 2, p. 137-149, abr./jun. 2004.

VeloZ, M. C. T.; NASCIMENTO-SChulZE, C.; CAMARGO, B. V. Representações sociais do envelhecimento. Psicologia: reflexão e crítica, Porto Alegre, v. 12, n. 2, p. 479-501. maio/ago. 1999.

VERGÈS, P. Programas informáticos para análise de semelhanças e evocações. Aix-en-Provence: LAMES-CNRS, 1998.

Recebido em: 29 de janeiro de 2010 Aceito em: 25 de maio de 2011 